старший преподаватель кафедрь социальной философии и социологии Института социальных наук

Иркутского государственного университета

\section{МЕЖДУНАРОДНАЯ АКАДЕМИЧЕСКАЯ МОБИЛЬНОСТЬ КАК ФАКТОР ГАРМОНИЗАЦИИ МЕЖГОСУДАРСТВЕННЫХ ОТНОШЕНИЙ}

Аннотация:

В статье представлены результаты исследования места и роли международной академической мобильности в процессе гармонизации межгосударственных отношений на современном этапе. Автор на основе теоретических и эмпирических данных обосновывает практическую значимость международной академической мобильности в решении глобальных конфликтов и вызовов XXI в.

Ключевые слова:

международная академическая мобильность, высшая школа, интернационализация высшей школы, государство, международные отношения, гармонизация, политика, международные конфликты.
Senior Lecturer, Department of Social Philosophy and Sociology, Institute of Social Sciences of Irkutsk State University

\section{INTERNATIONAL ACADEMIC MOBILITY AS A FACTOR OF HARMONIZATION OF INTERSTATE RELATIONS}

The article presents the results of the research on the place and role of international academic mobility in the process of harmonization of interstate relations at the present stage. Based on theoretical and empirical data the author proves the relevance of international academic mobility in resolving global conflicts and challenges of the 21 st century.

Keywords: international academic mobility, higher education, internationalization of higher education, state, international relations, harmonization, policy, international conflicts.

В современном мире согласованное взаимодействие и взаимовыгодное сотрудничество между государствами и нациями являются непременными условиями формирования глобального информационного пространства, в рамках которого становится возможным диалог культур в едином векторе общественного развития. В XXI в. многообразие социальных процессов, определяющих указанное взаимодействие, весьма обширно: в политической, экономической, культурной и прочих сферах. Вместе с тем квинтэссенция достижений и потенциального качественного роста в современных государствах сосредоточена в том числе вокруг высшей школы. По справедливому мнению Н.Н. Морозовой, «образование традиционно является той областью, которая во многом определяет уровень развития взаимоотношений между странами, задает направленность и темпы сотрудничества, обеспечивает их гармонизацию, наполнение нравственным и духовным контентом» [1, с. 45]. Следовательно, академические связи являются наиболее устойчивым и значимым фактором укрепления межгосударственных и в целом социальных отношений на международном уровне. Исходя из этого, актуальность проведенного исследования заключается в необходимости формирования механизма гармонизации межгосударственных отношений на основе активизации и расширения внешних академических связей.

Основной формой академических связей, «выходящих» за пределы государственных границ, является международная (внешняя) академическая мобильность. Механизм академической мобильности выражается в организации обучения, стажировок, производственных и исследовательских практик, деятельности студентов, аспирантов, преподавателей, научных и административных работников в образовательных организациях, расположенных за рубежом [2, с. 262]. Важно заметить, что интернационально мобильные представители академической среды, обладающие подобным «навыком XXI в.» - особый класс лиц, способность которых к эффективному участию в медиативных и гармонизационных международных процессах чрезвычайно высока. Однако, несмотря на отсутствие единого подхода к пониманию международной академической мобильности, для нее характерны следующие свойства, обусловливающие ее ценность в рассматриваемом контексте: а) создает условия и является гарантом эффеективного взаимодействия между государствами в области образования и науки на основе заключенных договоров и соглашений; б) обеспечивает развитие идеологии конкурентоспособности на мировом рынке образовательных услуг, стимулируя повышение качества высшего образования по всему миру; в) гармонизирует образовательные системы и, как следствие, межгосударственные отношения через систему социальных связей и отношений, возникающих в ходе реализации экспорта и импорта образовательных услуг. 
На фоне интенсификации межкультурных коммуникаций, стремительного развития сетевых взаимодействий, усиления миграционных потоков и обострения в глобальном масштабе отношений между Востоком и Западом потребность в развитии и расширении международной академической мобильности многократно возросла. В связи с этим многие государства выстраивают свои национальные стратегии интернационализации высшего образования и целенаправленно придают этому особое значение, используя показатель входящей и исходящей международной академической мобильности для включения своих университетов в топ глобальных рейтингов и достижения лидерства стран на мировой арене. Так, например, российская высшая школа имеет высокие показатели интернационализации (занимает 4-е место в мире) и ежегодно увеличивает коэффициент чистого притока мобильных студентов. Анализируя статистические данные Института статистики ЮНЕСКО, отчетливо видно, что среди стран мира по коэффициенту чистого притока мобильных студентов в 2014 г. лидируют страны - геополитические центры: США (776 030 чел. в год), Великобритания (399 118), Австралия (253 894), далее следуют Российская Федерация (158 156), Франция (156 365), Япония (99 447), Германия (93 233) [3].

Раскрывая суть конфликта культурно-антропологических матриц России и западного мира как источника информационных войн, А.П. Марков приходит к важным, на наш взгляд, выводам:

1. Частью национальной идеи должен стать образ России как центра евро-азиатской цивилизации (синтезирующей в себе восточную и западную культуры).

2. Россия должна стать центром гармонии цивилизаций (пространством консолидации народов и государств), гарантом сохранения миропорядка и противостояния глобальным угрозам - гарантом защиты международного права.

3. В России необходимо образовать модель этнокультурной и религиозной толерантности на основе многовекового опыта межнационального и межконфессионального взаимодействия в границах русского мира [4, с. 22].

P.А. Абдуразаков полагает, что сегодня «...от степени осознания российским обществом роли России в современной геополитической борьбе зависят... будущее нашей страны, ее самостоятельное развитие и суверенитет... Необходимо формирование... молодого поколения, которое обладало бы развитой политической культурой и культурой цивилизационной идентичности... следовало бы традициям гуманизма и толерантности» [5, с. 53-54].

Говоря о значении культурной составляющей международной академической мобильности, следует процитировать слова П.Л. Карабущенко: «Как базовый элемент “мягкой силы” культура способна решать вопросы, которые оказываются не по силе милитаризму. Культура - главный политический миротворец...» [6, с. 92]. В России, признавая важность развития международной академической мобильности на государственном уровне, с 2012 г. показатели международной деятельности вузов включают в число критериев общероссийской системы оценки эффективности деятельности образовательных организаций. Заметим, что при условии налаженного системного академического взаимодействия между странами Запада и государствами, на территории которых было образовано Исламское государство (запрещенная в России организация), идеологический фундамент для данного антиобщественного образования с большой долей вероятности не смог бы сложиться. То есть целый ряд современных геополитических проблем требует для своей стабилизации и разрешения непосредственного применения механизмов международной академической мобильности, которая позволит оппонирующим сторонам услышать и понять друг друга, сделав тем самым первый шаг к согласию и сотрудничеству. Так, по мнению западных ученых, «...возросшая научная мобильность открывает возможности для дальнейшей интеграции, культурного обмена и взаимопонимания всех участников» [7, р. 85].

Следовательно, предметно сводить государственную политику в области международной академической мобильности исключительно к повышению уровня конкурентоспособности и интеграции в международное научно-образовательное пространство стратегически недостаточно. Необходимо помнить о первостепенной цели такой политики - формировании положительного отношения к государству [8, с. 114]. Иными словами, международная академическая мобильность призвана способствовать адаптации государства к успешному отстаиванию своих интересов в мировом пространстве, и в этом смысле она ориентирована на внутреннее развитие государства.

Таким образом, практическая значимость международной академической мобильности в процессе гармонизации международных отношений заключается, по нашему мнению, в следующих положениях:

- в концептуально-ориентированном программном обеспечении государством академического сотрудничества и обмена, направленных на достижение целей и интересов национальной политики, с учетом базовых принципов и норм международной коммуникации (выработка «дорожных карт»);

- возможности нахождения «точек соприкосновения» между государствами, находящимися на разных уровнях взаимодействия (дружественном, нейтральном, конфронтационном и т. д.); 
- определении и реализации перспективных краткосрочных, среднесрочных и долгосрочных моделей (планов) взаимодействия стран для предупреждения, преодоления или минимизации (устранения) межгосударственных конфликтов;

- накоплении социального опыта управления схожими межгосударственными процессами (например, миграцией [9]), их изучении и прогнозировании на основе факторного анализа.

В заключение приходим к выводу, что международная академическая мобильность обеспечивает гармонизацию межгосударственных отношений, а ее имманентная способность предотвращать внешние конфликты, реагировать на глобальные вызовы и сглаживать социально-идеологические противоречия на геополитическом пространстве до конца не исследована, нуждается в дальнейшей комплексной проработке и апробации на основе имеющегося опыта интернационализации.

\section{Ссылки:}

1. Морозова Н.Н. Интеграционные процессы в сфере образовательного пространства // Ученые записки Череповецкого государственного университета. 2016. № 1 (5). С. 44-49.

2. Козлова Е.С., Кузьмин И.А. Международно-правовое регулирование академической мобильности как социального процесса в высшей школе // Вестник Иркутского государственного технического университета. 2013. № 9 (80). С. 261-268.

3. UNESCO Institute for Statistics (UIS) [Электронный ресурc]. URL: http://www.uis.unesco.org (дата обращения: 26.03.2017).

4. Марков А.П. Конфрликт культурно-антропологических матриц России и Запада как источник информационных войн // Вестник Кемеровского государственного университета культуры и искусств. 2016. № 36. С. 13-24.

5. Абдуразаков Р.А. Геополитическая социализация вчера и сегодня: к постановке проблемы // Вестник Дагестанского государственного университета. Серия 2: Гуманитарные науки. 2015. № 4. С. 53-59.

6. Карабущенко П.Л. Политические элиты и проблемы национальной безопасности // Государственное и муниципальное управление. Ученые записки СКАГС. 2015. № 3. С. 91-97.

7. Wende M. van der. International academic mobility: towards a concentration of the minds in Europe // European Review. 2015. Vol. 23, iss. S1. P. S70-S88.

8. Ц Цветкова Н.А., Ярыгин Г.О., Лопач О.В. Политика международной академической мобильности Российской Федерации // Азимут научных исследований: экономика и управление. 2015. № 4 (13). С. 108-115.

9. Товышева А.А. Причинно-факторный анализ закономерностей миграционных процессов в России // Современные тенденции развития науки и технологий : сб. науч. тр. по материалам VII междунар. науч.-практ. конф. (31 окт. 2015 г.). 2015. № 7, ч. VIII. C. 126-131.

\section{References}

Abdurazakov, RA 2015, 'Geopolitical socialization yesterday and nowadays: to the problem statement', Vestnik Dagestanskogo gosudarstvennogo universiteta. Seriya 2: Gumanitarnyye nauki, no. 4, pp. 53-59, (in Russian).

Karabushchenko, PL 2015, 'Political elites and national security problems', Gosudarstvennoye i munitsipal'noye upravleniye. Uchenyye zapiski SKAGS, no. 3, pp. 91-97, (in Russian).

Kozlova, ES \& Kuzmin, IA 2013, 'International legal regulation of academic mobility as a social process in higher education', Vestnik Irkutskogo gosudarstvennogo tekhnicheskogo universiteta, no. 9 (80), pp. 261-268, (in Russian).

Markov, AP 2016, 'Conflict of cultural and anthropological matrices of Russia and the West as a source of information warfare', Vestnik Kemerovskogo gosudarstvennogo universiteta kul'tury $i$ iskusstv, no. 36, pp. 13-24, (in Russian).

Morozova, NN 2016, 'Integration processes in educational space', Uchenyye zapiski Cherepovetskogo gosudarstvennogo universiteta, no. 1 (5), pp. 44-49, (in Russian).

Tovysheva, AA 2015, 'A causal chain analysis of the common factors of migration processes in Russia', Sovremennyye tendentsii razvitiya nauki i tekhnologiy: sb. nauch. tr. po materialam VII mezhdunar. nauch.-prakt. konf. (31 okt. 2015 g.), no. 7 , part VIII, pp. 126-131, (in Russian).

Tsvetkova, NA, Yarygin GO \& Lopach, OV 2015, 'The policy of international academic mobility of the Russian Federation', Azimut nauchnykh issledovaniy: ekonomika i upravleniye, no. 4 (13), pp. 108-115, (in Russian).

Wende, M van der, 'International academic mobility: towards a concentration of the minds in Europe', European Review, vol. 23, iss. S1, pp. S70-S88, https://doi.org/10.1017/s1062798714000799. 